\title{
Status of methylation and transcriptional activity of ecdysone receptor $E c R$ gene in the Colorado beetle Leptinotarsa decemlineata say after application of S-adenosylmethionine
}

\author{
Yuri Nikonorov \\ Institute of Biochemistry and Genetics \\ Ufa Federal research centre of RAS \\ Russia \\ griffinriders@mail.ru
}

\author{
Tansulpan Akhmetkireeva \\ Institute of Biochemistry and Genetics \\ Ufa Federal research centre of RAS \\ Russia \\ tansulpan.ufa@gmail.com
}

\author{
Galina Benkovskaya \\ Institute of Biochemistry and Genetics \\ Ufa Federal research centre of RAS \\ Russia \\ bengal2@yandex.ru
}

\section{Keywords - DNA methylation, Colorado potato \\ beetle, ecdysone receptor gene}

\section{Motivation and Aim}

Gene of ecdysone receptor coding the protein EcR belongs to superfamily of nuclear steroid receptors, which has an evident domain structure and is of great importance for insect development and reproducing [1]. In cells of different tissues protein EcR presents as a combination of its isoforms coded by some variants of mRNA generated consequently by alternative splicing and change in isoforms balance has phenotypical exhibition [2]. In the Colorado beetle Leptinotarsa decemlineata Say two variants of mRNA coding A and B1 isoforms with tissue-specific character of their number variations are described [3]. Our aim is the definition of DNA methylation character in separate loci of gene $E c R$ coding region in the Colorado beetle, investigation of environmental effects and detection of correlation between DNA methylation and transcriptional activity of $E c R$ gene.

\section{Methods and Algorithms}

Adult Colorado beetles sampled in potato plantation were used as an object. The source of methyl groups (Heptral - S-adenosylmethionine, SAM, Abbott Laboratories $\mathrm{GmbH}$, Germany) was applied as suspension ( $80 \mathrm{mg} / 10 \mathrm{ml}$ of water) for treatment of fresh potato leaves intended for beetles feeding. DNA and RNA were extracted from tissues of thorax and gonads of adults by phenoldetergent method. The presence of 5-methylcytosine in Colorado beetles DNA was determined by MSRE-PCR (methyl-sensitive PCR). Transcriptional activity of genes of ecdysone receptor $E c R$, DNA-methylase Dnmt1 and protein transporter of juvenile hormone $J u v$ was evaluated by qRTPCR with reference gene RP18.

Results: The presence of methylated cytosine in DNA coding the regions of $E c R$ gene in the L. decemlineata Say is of a specific character: DNA site for HpaII restrictase in exon distinctive for $\mathrm{B} 1$ isoform degraded completely under hydrolysis in all cases, i.e. it is constantly demethylated. Considerable part of DNA in exons specific for A isoform and constant for both isoforms is methylated permanently in a varying degree. In two months the addition of methyl group source (SAM) to food caused decrease of methylation level in coding region of $E c R$ gene in adults of both sexes. Content of mRNA of $E c R$ gene in cells of thorax increased 6,1-fold in males and 2,2-fold in females; in gonads it increased 7,7-fold and 9,1- fold respectively. The ratio of mRNA variants coding $\mathrm{A}$ and $\mathrm{B} 1$ isoforms changed to prevalence of $\mathrm{A}$-isoform in muscles as well as in gonads in males and females. At the same time mRNA content of Dmntlgene reduced to a certain degree and the content of mRNA of $J u v$ gene increased dramatically, especially in female gonads. Similar but more expressed changes in transcriptional activity of these genes were observed right after feeding beetles by nontreated by SAM potato leaves: in an hour after feeding we noted more than two-fold decrease of mRNA of Dnmt1 gene content and more than 10 -fold increase of mRNA of Juv gene content. However in this case transcriptional activity of EcR gene decreased 10fold.

\section{Conclusion}

Effect of SAM addition to food is of long-term character exhibited as change of methylation status and expression of $E c R$ gene in the Colorado beetle. We suggest that methylation of DNA takes part in regulation of mRNA splicing of $E c R$ gene. A considerable part of methyl group donors most probably includes in juvenile hormone metabolism. Initiation of this process activated by SAM treatment leads to deficit of endogenic donors of methyl groups the consequence of which is the phenomenon of DNA demethylation.

\section{ACKNOWLEDGMENTS}

Investigations was partially funded by RFBR No. 17-44020347-r_a.

\section{REFERENCES}

[1] L.M. Riddiford, P. Cherbas, J.W. Truman, "Ecdysone receptors and their biological actions", Vitam. Horm., 2000, vol. 60, pp. 1-73.

[2] W.S. Talbot, E.A. Swyryd, D.S. Hogness, "Drosophila tissues with different metamorphic responses to ecdysone express different ecdysone receptor isoforms", Cell, 1993, vol. 93, pp. 1323-1337.

[3] T. Ogura, C. Minakuchi, Y. Nakagawa, G. Smagghe, and H. Miyagawa, "Molecular cloning, expression analysis and functional confirmation of ecdysone receptor and ultraspiracle from the Colorado potato beetle Leptinotarsa decemlineata", FEBS J., 2005, vol. 272 (16), pp. 4114-4128 